\title{
Assessing impact of dual sensor enhanced flight vision systems on departure performance
}

\author{
Lynda J. Kramer ${ }^{* a}$, Timothy J. Etherington ${ }^{\mathrm{a}}$, Kurt Severance ${ }^{\mathrm{b}}$ and Randall E. Bailey ${ }^{\mathrm{a}}$ \\ aNASA Langley Research Center, MS 152, Hampton, VA, USA 23681-2199; \\ bNASA Langley Research Center, MS 472, Hampton, VA, USA 23681-2199
}

\begin{abstract}
Synthetic Vision (SV) and Enhanced Flight Vision Systems (EFVS) may serve as game-changing technologies to meet the challenges of the Next Generation Air Transportation System and the envisioned Equivalent Visual Operations (EVO) concept - that is, the ability to achieve the safety and operational tempos of current-day Visual Flight Rules operations irrespective of the weather and visibility conditions. One significant obstacle lies in the definition of required equipage on the aircraft and on the airport to enable the EVO concept objective. A motion-base simulator experiment was conducted to evaluate the operational feasibility and pilot workload of conducting departures and approaches on runways without centerline lighting in visibility as low as 300 feet runway visual range (RVR) by use of onboard vision system technologies on a Head-Up Display (HUD) without need or reliance on natural vision. Twelve crews evaluated two methods of combining dual sensor (millimeter wave radar and forward looking infrared) EFVS imagery on pilot-flying and pilotmonitoring HUDs. In addition, the impact of adding SV to the dual sensor EFVS imagery on crew flight performance and workload was assessed. Using EFVS concepts during 300 RVR terminal operations on runways without centerline lighting appears feasible as all EFVS concepts had equivalent (or better) departure performance and landing rollout performance, without any workload penalty, than those flown with a conventional HUD to runways having centerline lighting. Adding SV imagery to EFVS concepts provided situation awareness improvements but no discernible improvements in flight path maintenance.
\end{abstract}

Keywords: Enhanced Flight Vision Systems, Synthetic Vision Systems, Combined Vision Systems, Forward Looking Infrared, Millimeter Wave Radar, DO-341

\section{INTRODUCTION}

The U.S. air transportation system is undergoing a transformation to accommodate the movement of large numbers of people and goods in a safe, efficient, and reliable manner. ${ }^{1}$ One of the key capabilities envisioned to achieve the Next Generation Air Transportation System (NextGen) is the concept of equivalent vision operations (EVO). EVO is the ability to achieve the safety of current-day Visual Flight Rules (VFR) operations and maintain the operational tempos of VFR irrespective of the weather and visibility conditions.

Significant delays occur in today's National Airspace System (NAS) when low visibility conditions prevail as Instrument Flight Rules (IFR) are invoked which invariably lead to reductions in arrival/departure operational tempos and associated time delays in surface operations. ${ }^{2,3}$ This contribution to delay is expected to continue, if not increase. ${ }^{4}$ One significant challenge for EVO is the definition of required equipage on the aircraft and on the airport. With today's equipment and regulations, significant investment is required in on-board equipment for navigation, surveillance, and flight control and on the airport for precision guidance systems and approach lighting systems for "all-weather" landing capability (i.e., Category III operations to all runway ends). The levels of equipment redundancy, capability, maintenance, performance, and crew training dramatically increase as landing visibility minima decrease.

Operational tempos are significantly reduced during low visibility conditions as pilots must maintain their situation awareness (e.g., awareness of ownship geographic position with respect to the airport, other traffic, and ground vehicles) to ensure the continuation of safe, efficient air and ground operations. Departures are affected by an even greater degree because standard low visibility takeoffs require 1600 feet ( $\mathrm{ft}$ ) visibility which is much greater than that required to conduct taxi operations. Lower than standard takeoff minimums can be authorized but they require additional airport ground

*lynda.j.kramer@nasa.gov; phone 1757 864-8146; fax 1757 864-7793 
infrastructure (e.g., RVR sensors, runway centerline lighting/markings, etc.).

Synthetic Vision Systems (SVS) and Enhanced Flight Vision System (EFVS) flight-deck based technologies offer a means of providing EVO capability without significant airport infrastructure investment while potentially increasing efficiency and throughput during low visibility terminal area operations. NASA Langley Research Center is conducting research to ensure effective technology development and implementation of regulatory and design guidance to support introduction and use of onboard SVS/EFVS advanced flight deck vision system technologies in NextGen operations.

\section{BACKGROUND}

SVS is a computer-generated image of the external scene topography that is generated from aircraft attitude, high-precision navigation, and data of the terrain, obstacles, cultural features, and other required flight information. EFVS is a real-time electronic image of the external scene generated by imaging sensors, such as a Forward-Looking InfraRed (FLIR) or Millimeter Wave Radar (MMWR), and presented on a head-up display (HUD). Both SVS and EFVS are onboard visionbased technologies intended to supplement or enhance the natural vision of the pilot in low visibility conditions. Combined Vision Systems (CVS) use a combination of SVS and EFVS for presentation to the pilot.

NASA and others have developed and shown that SVS technologies provide significant improvements in terrain awareness and reductions for the potential of Controlled-Flight-Into-Terrain incidents/accidents, ${ }^{3,4}$ improvements in flight technical error to meet Required Navigation Performance criteria, ${ }^{7-9}$ and improvements in situation awareness without increased workload compared to current generation cockpit technologies. ${ }^{10-12}$ As such, SVS, often displayed on a head-down display (HDD), is emerging as standard equipage for Part 23 and Part 25 flight decks even though, to date, no operational credit is obtained from equipage. ${ }^{13}$

EFVS capability on a HUD using FLIR sensor technology has garnered a significant share of the business aircraft market and is growing in Part 121 and 135 operations. ${ }^{14}$ EFVS provides many of the same operational benefits as SVS technology, but it uses a real-time view of the external environment, independent of the aircraft navigation solution or database. These differences, in part, enable operational credit with use of an approved EFVS. In 2004, Title 14 of the Code of Federal Regulations (CFR) Section (§) 91.175 was amended to enable operators conducting straight-in instrument approach procedures (in other than Category II or Category III operations) to descend below the published Decision Altitude (DA), Decision Height (DH) or Minimum Descent Altitude (MDA) down to 100 feet ( $\mathrm{ft}$ ) above touchdown zone elevation (TDZE) using an approved EFVS in lieu of natural vision. (To descend below 100 feet above the TDZE, the required visual references for landing must be distinctly visible and identifiable by the pilot using natural vision.) An approved EFVS must meet the requirements of $\S 91.175(\mathrm{~m})$ and the use of a HUD or an equivalent display is required.

Synthetic and Enhanced Vision Systems (SEVS) technologies, such as SVS/EFVS in combination with HDD/HUD, form the basis for an electronic display of visual flight references for the flight crew. Integrating these SEVS displays with conformal symbology provides important situation, guidance, and/or command information as necessary and/or appropriate to enable all weather approach and landing operations. The primary reference for maneuvering the airplane is based on what the pilot sees electronically through the SEVS, in lieu of or supplemental to the pilot's natural vision, in low visibility conditions.

The key concept for 14 CFR $\S 91.175$ is that an EFVS can be used in lieu of natural vision from the DA/DH/MDA to 100 $\mathrm{ft}$ height above the TDZE provided the visibility of the enhanced vision image meets or exceeds the published visibility required for the approach being flown and the required visual references are clearly identified. Minimum aviation system performance standards for EFVS are available in RTCA DO-315 ${ }^{15}$. RTCA DO-315 also provides performance standards for SVS but without operational credit.

The FAA has issued a notice of proposed rulemaking ${ }^{16}$ to expand operational credit for EFVS beyond what is currently authorized under 14 CFR $\S 91.175$. Specifically, the new regulation (14 CFR §91.176) would permit an EFVS to be used in lieu of natural vision during a straight-in precision instrument approach procedure or an approach with approved vertical guidance. The new rule would also permit EFVS to be used during touchdown and rollout and add operational benefits for Part 91 Subpart K, 135, and 121 operators. FAR $\$ 135.219$ would be amended to allow dispatch to a destination that is below minimums if the aircraft is EFVS-equipped and the operator is authorized for EFVS operations through OpSpecs (Operations Specifications), MSpecs (Management Specifications), or LOA (Letters of Authorization). Also, FAR $\$ 135.225$ would be modified to enable an EFVS-equipped aircraft and trained crew to initiate or continue an approach when the destination airport is below authorized minimums. These upcoming rule changes support EVO through use of 
an onboard flight-deck based EFVS rather than necessitating additional ground infrastructure equipment and operating procedures. An EFVS-equipped aircraft and qualified crew could dispatch and continue an approach to a landing, even when the destination airport is below authorized minimums, solely through the use of an electronic (sensor) image. ${ }^{17}$

The FAA proposed EFVS rule change does not explicitly impose a RVR limitation but mentions that initial implementations of EFVS operations to touchdown and rollout may be limited to visibilities of no lower than $1000 \mathrm{ft}$ RVR because airworthiness and certification criteria have not been developed to support EFVS operations below $1000 \mathrm{ft}$ RVR. Past NASA simulation research ${ }^{18}$ supports the viability of this expanded EFVS operational credit where it was shown that using a single sensor EFVS (FLIR imagery on a HUD) to hand-fly approaches through touchdown resulted in excellent localizer tracking performance and an improvement in glideslope tracking performance in visibility as low as 1000 RVR. Natural vision of 700 to $1000 \mathrm{ft}$ RVR has been shown to be sufficient to mitigate a complete failure of the single sensor EFVS. FLIR is dependent upon atmospheric conditions. It works well in smoke, haze and at night, but has degraded performance in some fog, rain, and snow conditions. ${ }^{19}$ All currently approved EFVS ${ }^{16}$ use FLIR (single sensor imagery) on a HUD.

RTCA DO-341 ${ }^{20}$ was drafted to establish minimum performance standards for EVFS operations on straight-in instrument approach procedures with published vertical guidance to touchdown, landing, and roll-out to a safe taxi speed in visibility as low at $300 \mathrm{ft}$ RVR. Criteria are established such that the combination of all systems used during this EFVS operation shall be designed, tested, and certified to a level of safety appropriate for the phase of flight and the intended operation. As such, a fail-operational EFVS design is necessary - consistent with other systems and subsystems used for the same intended function and phase of flight (e.g., instrument landing systems, autoland systems, and navigation systems) without the need or reliance of the crew's natural vision. In these extremely low visibility conditions, there is not sufficient natural vision for the flight crew to mitigate certain EFVS failure conditions which might have catastrophic consequences.

DO-341 specifies that both the pilot-flying (PF) and pilot-monitoring (PM) have an independent EFVS HUD as well as an alternate display for enhanced vision (EV) sensor imagery. It is envisioned that more than one sensor will be needed for EFVS operations below $1000 \mathrm{ft}$ RVR. FLIR sensor technology used in current-production EFVS is limited in its ability to work in extreme low visibility conditions (e.g., <700 ft RVR). ${ }^{19,21}$ MMWR technologies show promise for working in nearly all operationally relevant atmospheric conditions but the image resolution is not as good as FLIR.

Takeoff minimums only apply to persons operating an aircraft under parts 121, 125, 129, or 135 (for instance, see 14 CFR 121.651). It references company OpSpecs and $\$ 91.175$ and Part 97. OpSpecs C056 is issued to all Part 121 carriers and spells out standard takeoff minimums of 1 mile visibility for twin engine and $1 / 2$ mile visibility for more than two engines and RVR reporting, if available, is controlling. OpSpecs C078 is issued for lower than standard visibility and applies for certain operations at airports with additional lighting and/or markings. The potential credits for airport equipage is shown in Table 1. Lower than standard visibility credits are dependent upon the presence of aircraft infrastructure, specifically, high intensity runway lights (HIRL), runway centerline lights (CLL), or runway centerline markings (RCLM). RVR sensors are used to control the operation, providing assurance for adequate natural visibility through the beginning, midpoint, and end of the departure runway. The lowest visibility minima (300 RVR) requires augmentation with an approved HUD takeoff guidance system and a high integrity, highly accurate signal-in-space defining the runway centerline as well as special crew training and environmental limitations (e.g., crosswinds of less than 15 knots).

Current OpSpecs do not contain operational credit for EFVS take-off operations or reductions in takeoff minima. The FAA and RTCA SC-213 are currently investigating operational credit for these operations. Although regulatory changes are not expected to be required, research in nominal and off-nominal operations will be required. 
Table 1: OpSpecs C078/C079

\begin{tabular}{|c|c|}
\hline Serviceable Runway Visual Aid Required & Lowest Allowable Takeoff Minimum Authorization \\
\hline \multicolumn{2}{|l|}{ If an RVR sensor is not available: } \\
\hline $\begin{array}{l}\text { Adequate visual reference, or any one of the following: } \\
\text { HIRL/CLL/RCLM }\end{array}$ & $1 / 4 \mathrm{SM}(400 \mathrm{~m})$ \\
\hline If an RVR sensor is available: & $\begin{array}{l}\text { Note: Below RVR } 1600 \text {, two operating RVR sensors are required. } \\
\text { All operating } R V R \text { sensors are controlling (except per the note } \\
\text { below for far-end sensors). }\end{array}$ \\
\hline $\begin{array}{l}\text { Adequate visual reference, or any one of the following: } \\
\text { HIRL/CLL/RCLM }\end{array}$ & $\begin{array}{l}\text { RVR } 1600(500 \mathrm{~m}) / \mathrm{NR} / \mathrm{NR} \\
\text { Mid-point can substitute for an unavailable touchdown. }\end{array}$ \\
\hline $\begin{array}{l}\text { Day: CLL or RCLM or HIRL } \\
\text { Night: CLL or HIRL }\end{array}$ & RVR $1200(350 \mathrm{~m}) / 1200(350 \mathrm{~m}) / 1000(300 \mathrm{~m})$ \\
\hline RCLM and HIRL, or CLL & RVR $1000 / 1000 / 1000(300 \mathrm{~m})$ \\
\hline HIRL and CLL & RVR 600/600/600 $(175 \mathrm{~m})$ or RVR 500/500/500 $(150 \mathrm{~m})$ \\
\hline $\begin{array}{l}\text { With an approved HUD takeoff guidance system, HIRL, CLL, } \\
\text { and CAT III ILS }\end{array}$ & RVR 300/300/300 (75 m) \\
\hline
\end{tabular}

NR: Not Required

\section{OVERVIEW}

A motion-based simulation experiment was conducted to evaluate the operational feasibility, pilot workload, and pilot acceptability of conducting standard instrument departures and straight-in instrument approaches with published vertical guidance to landing, touchdown, and rollout to a safe taxi speed in visibility as low as $300 \mathrm{ft}$ RVR by use of vision system technologies (EFVS and SVS) on a head-up display without need or reliance on natural vision. Departures were conducted through transition and cleanup of the aircraft. Limited taxi segments were conducted for both taxi out and taxi from initial clearing of the runway until the first straight segment of the taxi to the gate.

Twelve crews evaluated two methods of combining dual sensor (MMWR and FLIR) EFVS imagery on PF and PM HUDs. In addition, the crews evaluated three CVS HUD concepts to assess the complementary use of SVS which is unaffected by weather or time of day and EV sensors which offer real-time imaging detection of objects not in the SVS database. An Instrument Landing Systems (ILS) was used for approach and departure guidance and a simulated Global Positioning System/Wide Area Augmentation System (GPS/WAAS) was used for the navigation component of the on-board SVS. Crews assessed dual sensor EFVS/CVS HUD concepts during approach, landing, taxi and departure operations in $300 \mathrm{ft}$ RVR. Another key element of the testing entailed investigating the crew's awareness and reaction to non-normal events (e.g., EFVS HUD failure) that were unexpectedly introduced into the experiment. These non-normal events are critical determinants in the underlying safety of all-weather operations.

The current paper documents the taxi and takeoff performance, landing rollout performance, and pilot workload from this experiment. Dual sensor EFVS/CVS approach and landing performance ${ }^{22}$ and crew decision making during off nominal approach and departure events ${ }^{23}$ are addressed in separate publications.

\section{METHOD}

\subsection{Subjects}

Twenty-four pilots (12 crews total), representing 5 airlines ( 7 crews), a cargo carrier ( 1 crew) and business aviation (4 crews), participated in the experiment. Crews were paired by airline to ensure crew coordination and cohesion with regard to operating procedures. All subjects were Airline Transport Pilot rated, had at least 100 hours of HUD experience as pilot in command, and had prior EV or EFVS experience. The business aviation crews had the most recent experience with EFVS. All subjects were male. The Captains' average age was 57.7 years with an average of 1,988 HUD flight hours, 23 years of commercial flying and 14.8 years of military flying. The First Officers' average age was 49.7 years with an average of 1,255 HUD flight hours, 14.8 years of commercial flying and 14 years of military flying. The Captain was the designated PF throughout all the trials and the First Officer served as the PM. 


\subsection{Apparatus}

The study was conducted in the NASA Langley Research Center (LaRC) Research Flight Deck (RFD) simulator (see Figure 1). The study was conducted in motion on a hexapod simulation system. The RFD is representative of a state-ofthe-art subsonic transport airplane with fully reconfigurable flight deck systems. The RFD uses a 200 degree x 40 degree field-of-view out-the-window collimated visual system. The flight deck includes four large landscape-format Liquid Crystal Displays configured as two primary flight displays, two navigation displays, and engine instruments and crew alerting system (EICAS) displays with cursor controllers and multifunction controls on the center aisle stand. Electronic flight bag (EFB) displays are outboard on each pilot's side. Movable throttles, including a back-driven auto-throttles, were implemented. Active side stick controllers, fully-coupled side-to-side, were provided for manual aircraft control. Dual HGS-6700 head-up displays are installed providing approximately 42 degree Horizontal by 30 degree Vertical field-ofview. The HUD uses overhead brightness controls for symbology and brightness and contrast for imagery. A castle switch on each side-stick controls the HUD image and symbology declutter selections. Checklists and approach charts were shown on the EFB.

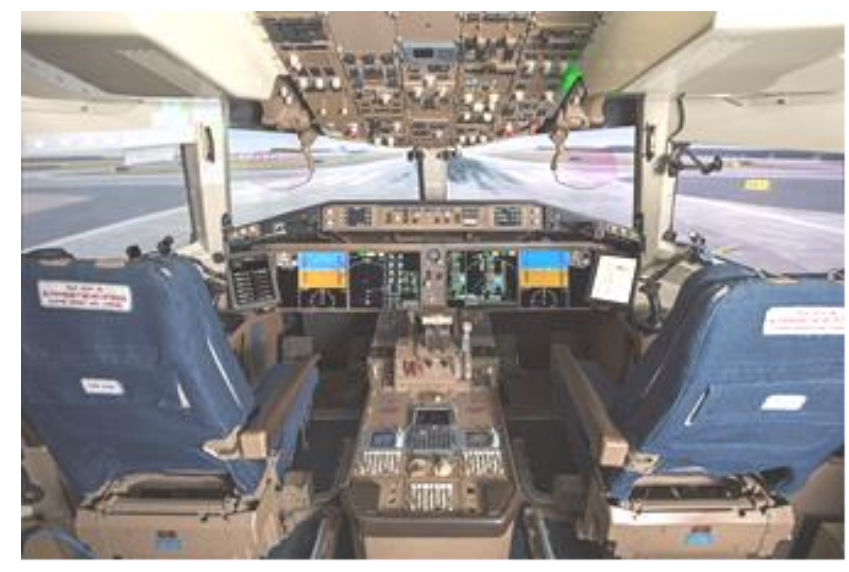

Figure 1. Research Flight Deck

Three detailed databases were developed for the study. ${ }^{22}$ First, a detailed out-the-window visual database was created for the Memphis (TN) International Airport and surrounding area. From this detailed database, two additional databases were created using material-coding for all objects to associate infrared (IR) and radar properties onto each feature. The IR database was rendered using standard tools developed by Rockwell Collins Simulation and Training Systems, modeling a short-wave/mid-wave cooled IR sensor. The MMWR simulation was rendered using a physics-based modeling process developed at NASA LaRC. This model produced a detailed 3D MMWR depiction that was mapped to a B-scope radar image (range/azimuth/intensity data) and then transformed to a C-scope camera image (azimuth/elevation/intensity). Radar parameters simulated a $94 \mathrm{GHz}$ radar with a 2 mile range, using 5 meter range bins and 0.5 degree angular width, simulating emerging 3D MMWR systems.

Two different methods of combining the FLIR and MMWR imagery, referred to as Blended and Slant Range, were explored in this experiment. The two methods provided experimental variation of the information content (i.e., pilot awareness of imagery sources) and the resultant image contrast.

In the Blended method, the FLIR and MMWR imagery were aligned to one another and averaged together. Since image blending often results in a loss of contrast, the Contrast-Limited Adaptive Histogram Equalization (CLAHE) contrast algorithm was applied in real-time to reveal the salient features of the scene. The method provided good image contrast without obvious distinction of the image data sources.

In the Slant Range method, the heuristics that each sensor works best within a nominal slant-range distance from the aircraft in given RVR conditions were applied. The MMWR characteristics were fixed, and thus, its performance including maximum and minimum range was invariant within the weather and atmospheric properties in this simulation. The FLIR simulation was tuned to characterize measured flight test performance data. Using these guidelines, FLIR (point light sources) provided good detection in front of the aircraft to about 2 times the measured RVR, followed by MMWR with an effective range to $2.0 \mathrm{~nm}$. The FLIR was shown in the image region closest to the aircraft, followed by only MMWR out 
to $2.0 \mathrm{~nm}$. A small region of imagery overlap was blended between FLIR and MMWR to lessen the seams in the image. The method provides non-uniform image contrast but with more obvious distinction of the image data sources.

To alleviate aliasing effects in the EFVS HUD imagery, a fast smoothing operation was applied to both the Blended and Slant Range methods.

\subsection{Experimental Design}

The study used a partial $7 \times 2 \times 4$ randomized block design. The resultant design for the approach portion of the test is shown in Figure 2, resulting in 18 nominal experimental configurations/scenarios.

Two operational baseline HUD concepts, representing approved HUD operations in today's National Airspace System, were a critical part of the configuration/scenario design. The first operational baseline concept was a conventional HUD (symbology only, no EV) flown in $1800 \mathrm{ft}$ RVR which is the lowest visibility authorized to manually fly a HUD for Category (Cat) 1 approach with $200 \mathrm{ft}$ DH. The second operational baseline concept was a FLIR EFVS which is the only currently certified EFVS, flown in $1000 \mathrm{ft}$ RVR.

The EV imagery (FLIR) shown on the HUD was confined to the 20 degree H x 15 degree V sensor window which corresponds to the minimum field-of-view as per RTCA DO-315a.

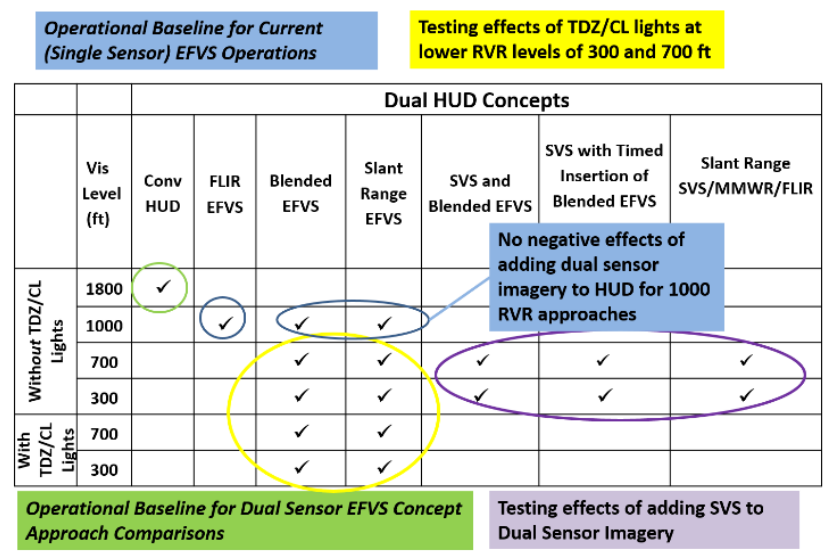

Figure 2. Nominal Approach Matrix

Five dual sensor (MMWR and FLIR) HUD Vision System (VS) concepts (2 EFVS, 3 CVS) were evaluated. The Blended and Slant Range methods were the two EFVS HUD concepts tested. The sensory imagery in these two conditions was confined to the $20^{\circ} \mathrm{H} \mathrm{x} 15^{\circ} \mathrm{V}$ HUD sensor window, corresponding to the minimum field-of-view as per RTCA DO-341 (and identical to DO-315a).

All three CVS HUD concepts employed SVS imagery (full-time) outside the EFVS sensor window, but differed in how and when the SVS imagery was drawn within the sensor window. ${ }^{22}$

In Figure 3, two of the CVS HUD Concepts are shown - SVS/Blended (left) and SVS/Slant Range (right). 

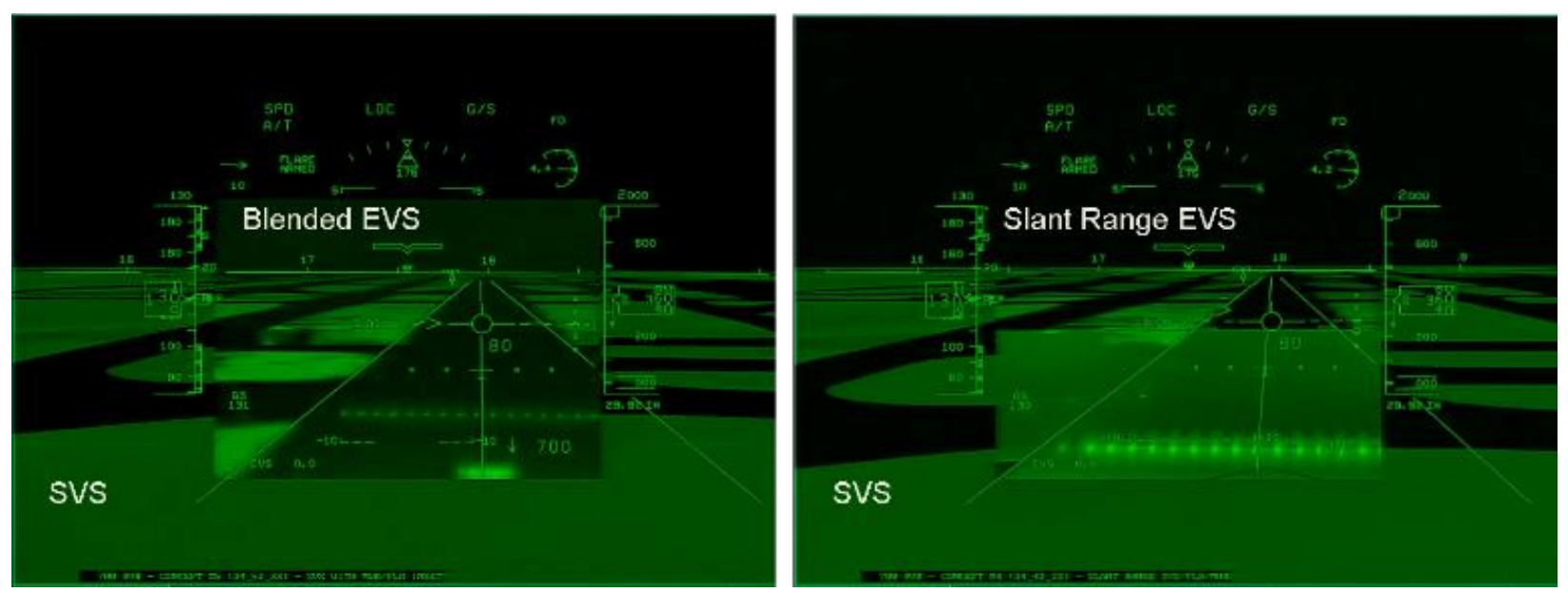

Figure 3. Two CVS HUD Formats - SVS/Blended EFVS (left) and SVS/Slant Range EFVS (right).

The crews also flew three additional approaches with the following failures:

- PF complete HUD failure was presented using the Blended EFVS concept in 300 RVR with 10 knots of right cross-wind on Runway 18L

- PM HUD failure was presented using the Slant Range EFVS concept in 700 RVR with 10 knots of left crosswind on Runway 36R

- EFVS system failure was tested in 700 RVR on Runway 36C with between-subject testing presented on either Blended EFVS concept or SVS and Blended with EFVS concept

The study used a partial $5 \times 2$ randomized block design for departures. The design details are shown in Figure 4, including a description of cross effects. The conventional HUD (symbology only; no imagery) was tested in 300 RVR on a runway with centerline lighting, using the HGS-6700 low visibility takeoff guidance. The EFVS concepts were tested without centerline lights in $300 \mathrm{RVR}$ to test the elimination of lighting requirements for departure operations.

An engine failure on departure was used to force a rejected takeoff (RTO) and this condition was tested twice, once with the Slant Range EFVS concept and once with the conventional HUD symbology, with the failure order counterbalanced. This resulted in seven departure scenarios total with two resulting in an RTO.

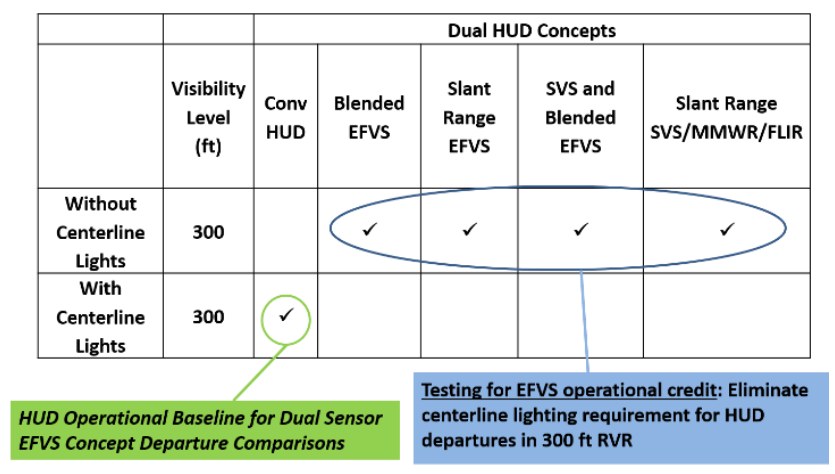

Figure 4. Nominal Departure Matrix

To enable the participants to more easily make comparisons on display concepts, the RVR was blocked on both approach and departure runs so that participants were shown all concepts in one visual condition and then the other. The runs within each visibility block were randomized. The block order was also randomized. A total of 28 runs were flown by each set of participants. 


\subsection{Independent Variables}

The independent variables for approach were:

1) Seven HUD display concepts consisting of two baselines, two methods (Blended and Slant Range) of displaying FLIR and MMWR information and three ways of combining synthetic vision information to the FLIR and MMWR display concepts

2) With and without touchdown and centerline lighting

During the HUD experimental runs, a synthetic vision PFD with an identical 20 degree $\mathrm{H}$ by 15 degree $\mathrm{V}$ sensor window was displayed to both the PF and PM. The PFD was used as an alternate display for EVS as per RTCA DO-341. The headdown primary and navigation display format was invariant.

The independent variables for departure were:

1) Five HUD display concepts consisting of a baseline, two methods (Blended and Slant Range) of displaying FLIR and MMWR information, and two methods of combining synthetic vision information to the FLIR and MMWR display concepts

2) With and without centerline lighting

The operational baseline for these comparisons was a conventional HUD (symbology only, no EV) departing on a runway with centerline lighting in $300 \mathrm{RVR}$ which is the lowest visibility currently authorized for takeoffs. Both the operational baseline and EFVS/CVS departure runs employed HIRL, serviceable RCLM, front course localizer guidance, and an approved HUD takeoff guidance system.

\subsection{Dependent Variables}

During each approach and landing run, path error, pilot control inputs, touchdown performance (sink rate and speed at touchdown, longitudinal and lateral landing distance), and rollout to a safe taxi speed performance (lateral distance from centerline, runway occupancy time, runway exit ground speed) were measured for analysis. During each departure run, lateral distance from centerline during takeoff roll and departure heading during climbout were measured for analysis.

After each run, pilots completed the Air Force Flight Test Center (AFFTC) Workload Estimate Scale ${ }^{24}$ (see Figure 5) and Likert-type questions on the usability of the HUD VS concept used for the aircraft operation (approach, taxi, departure) they had just conducted (see Figures 6-8). After data collection was completed, crews provided rank orders on which HUD VS concept (Blended, Slant Range, SVS/Blended, SVS/Timed Insertion of Blended, SVS/Slant Range) they preferred to fly with in visibilities as low as $300 \mathrm{ft}$ RVR. Crews were also administered the Situation Awareness - Subjective Workload Dominance (SA-SWORD) $)^{25}$ technique to evaluate the HUD VS formats. Through a semi-structured interview, the pilots also commented on the operational benefits/detriments observed with regard to 1) the blended method, 2) the slant range method, and 3) adding SVS to the EFVS imagery.

\begin{tabular}{|c|l|}
\hline & \multicolumn{1}{|c|}{$\begin{array}{c}\text { AFFTC Workload Estimate } \\
\text { (On the sheet provided, write the number of the statement which best describes the } \\
\text { MAXIMUM workload you experienced during the past work period.) }\end{array}$} \\
\hline 1 & Nothing To Do; No System Demands \\
\hline 2 & Light Activity; Minimum Demands \\
\hline 3 & Moderate Activity; Easily Managed; Considerable Spare Time \\
\hline 4 & Busy; Challenging But Manageable; Adequate Time Available \\
\hline 5 & Very Busy; Demanding To Manage; Barely Enough Time \\
\hline 6 & Extremely Busy; Very Difficult; Non-Essential Tasks Postponed \\
\hline 7 & Overloaded; System Unmanageable; Important Tasks Undone \\
\hline \hline
\end{tabular}

Figure 5. Air Force Flight Test Center Workload Scale 


\begin{tabular}{|c|c|c|c|c|c|c|c|}
\hline $\begin{array}{l}\text { Post-Run APPROACH } \\
\text { Ratings } \\
\text { On the sheet provided, write the number } \\
\text { which bests corresponds to your rating of } \\
\text { agreement with each statement based on } \\
\text { the HUD EFVS concept you just } \\
\text { evaluated. }\end{array}$ & $\begin{array}{c}\text { Strongly } \\
\text { Disagree } \\
1 \\
1\end{array}$ & $\begin{array}{l}\text { Disagree } \\
\qquad 2\end{array}$ & $\begin{array}{c}\text { Slightly } \\
\text { Disagree }\end{array}$ & $\begin{array}{c}\text { Neither } \\
\text { Agree or } \\
\text { Disagree }\end{array}$ & $\begin{array}{l}\text { Slightly } \\
\text { Agree }\end{array}$ & $\begin{array}{l}\text { Agree } \\
6\end{array}$ & $\begin{array}{c}\begin{array}{c}\text { Strongly } \\
\text { Agree }\end{array} \\
7\end{array}$ \\
\hline $\begin{array}{l}\text { Q1. Prior to DH, I was able to } \\
\text { pick up the necessary visual } \\
\text { references to continue the } \\
\text { approach or landing. }\end{array}$ & & & & & & & \\
\hline $\begin{array}{l}\text { Q2. The landing visual } \\
\text { references were visible and } \\
\text { identifiable no lower than } 100 \\
\text { ft AFL (i.e., the runway and } \\
\text { touchdown zone). }\end{array}$ & & & & & & & \\
\hline $\begin{array}{l}\text { Q3. There was sufficient time } \\
\text { to recognize and identify the } \\
\text { required visual references. }\end{array}$ & & & & & & & \\
\hline $\begin{array}{l}\text { Q4. The visual information } \\
\text { provided sufficient cues to } \\
\text { flare and land. }\end{array}$ & & & & & & & \\
\hline $\begin{array}{l}\text { Q5. I was able to maintain } \\
\text { lateral alignment with the } \\
\text { runway. }\end{array}$ & & & & & & & \\
\hline $\begin{array}{l}\text { Q6. I was able to complete the } \\
\text { approach and land safely. }\end{array}$ & & & & & & & \\
\hline
\end{tabular}

Figure 6. Post-Run Approach Questionaire

\begin{tabular}{|c|c|c|c|c|c|c|c|}
\hline $\begin{array}{l}\text { Post-Run TAXI } \\
\qquad \text { Ratings } \\
\text { On the sheet provided, write the } \\
\text { number which bests corresponds } \\
\text { to your rating of agreement on the } \\
\text { HUD EFVS concept you just } \\
\text { evaluated. }\end{array}$ & 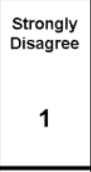 & $\begin{array}{l}\text { Disagree } \\
\qquad 2\end{array}$ & $\begin{array}{c}\begin{array}{c}\text { Slightly } \\
\text { Disagree }\end{array} \\
3\end{array}$ & $\begin{array}{c}\text { Neither } \\
\text { Agree or } \\
\text { Disagree }\end{array}$ & $\begin{array}{c}\begin{array}{c}\text { Slightly } \\
\text { Agree }\end{array} \\
5\end{array}$ & $\begin{array}{c}\text { Agree } \\
6\end{array}$ & $\begin{array}{c}\begin{array}{c}\text { Strongly } \\
\text { Agree }\end{array} \\
7\end{array}$ \\
\hline $\begin{array}{l}\text { Q1. EFVS improved my } \\
\text { ability to taxi. }\end{array}$ & & & & & & & \\
\hline $\begin{array}{l}\text { Q2. The Field-of-Regard } \\
\text { of the EFVS was } \\
\text { sufficient to taxi. }\end{array}$ & & & & & & & \\
\hline $\begin{array}{l}\text { Q3. I was able to safely } \\
\text { taxi the aircraft. }\end{array}$ & & & & & & & \\
\hline
\end{tabular}

Figure 7. Post-Run Taxi Questionaire

\begin{tabular}{|c|c|c|c|c|c|c|c|}
\hline $\begin{array}{l}\text { Post-Run } \\
\text { DEPARTURE } \\
\text { Ratings } \\
\text { On the sheet provided, wite the } \\
\text { number which bests corresponds } \\
\text { to your ratithg of agreement on } \\
\text { the HUD EFV concept you just } \\
\text { evaluated. }\end{array}$ & $\begin{array}{c}\text { Strongly } \\
\text { Disagree }\end{array}$ & $\begin{array}{l}\text { Disagree } \\
\qquad 2\end{array}$ & $\begin{array}{c}\begin{array}{c}\text { Slightly } \\
\text { Disagree }\end{array} \\
3\end{array}$ & $\begin{array}{c}\text { Neither } \\
\text { Agree or } \\
\text { Disagree }\end{array}$ & $\begin{array}{l}\text { Slightly } \\
\text { Agree }\end{array}$ & Agree & $\begin{array}{c}\begin{array}{c}\text { Strongly } \\
\text { Agree }\end{array} \\
7\end{array}$ \\
\hline $\begin{array}{l}\text { Q1. I was able to } \\
\text { position the aircraft on } \\
\text { runway centerline using } \\
\text { the EFVS in preparation } \\
\text { for takeoff roll. }\end{array}$ & & & & & & & \\
\hline $\begin{array}{l}\text { Q2. I was able to } \\
\text { maintain centerline } \\
\text { during takeoff roll. }\end{array}$ & & & & & & & \\
\hline $\begin{array}{l}\text { Q3. I was able to } \\
\text { maintain runway } \\
\text { heading during initial } \\
\text { climbout. }\end{array}$ & & & & & & & \\
\hline $\begin{array}{l}\text { Q4. I was able to safely } \\
\text { complete the departure. }\end{array}$ & & & & & & & \\
\hline
\end{tabular}

Figure 8. Post-Run Departure Questionaire

\subsection{Procedures}

Participants received an introductory briefing and informed consent, eye/head tracker calibration, extensive briefing of display concepts and procedures for EFVS approaches, simulation familiarization and training, two days of data collection, and a post-test interview and debrief. The training material included significant detail on all five display concepts and general procedures used for EFVS including required visual references needed to complete the approach using EFVS. Training consisted of cockpit familiarization and pointing out how the different image sources were affected by night and reduced visibility conditions. Autoland approaches were conducted using various visibility conditions encountered in the study with each of the five concepts. The participants were instructed to remove the HUD symbology and look only at the 
imagery for the autoland approaches. The crews then conducted hand-flown approaches with auto-throttles engaged for each of the five display concepts using the procedures and callouts expected for the study. A go-around was commanded by Air Traffic Control on the final approach run to train go-around procedures in the simulator. Initial training was done with motion off to facilitate the Principal Investigator (PI) standing and pointing out switches and display features. When the crew started hand-flying the approaches during training, the motion system was engaged. Departure training was conducted from the end of the runway with the last departure ending in an aborted takeoff initiated by the PI calling reject.

All approaches were conducted to the Memphis International Airport north/south runways. Approaches to the north runways (36L, 36C, 36R) had touchdown zone, centerline, and Surface Movement Guidance and Control System (SMGCS) lighting on the ground including lead-on/lead-off lights and taxi centerline lighting while approaches to the south runways (18L, 18C, 18R) did not. Approach Lighting System with Sequenced Flashing Lights (ALSF-2) approach lighting systems (ALS) were used on the north runways and Medium-intensity Approach Lighting System with Runway Alignment Indicator Lights (MALSR) ALS were used on the south runways.

Data collection proceeded after the training runs were complete and a complete matrix of 28 runs was conducted. After each run, the post-run measures (Figures 5-8) were administered. Crews were handed sheets to quietly mark their individual ratings to remove experimenter and subject bias. Upon completion of all runs, the post-test measures (rank order, SA-SWORD paired comparisons) were administered. Then, subjects were debriefed with a guided questionnaire and semi-structured discussions.

\section{RESULTS}

Dual sensor EFVS approach and landing performance ${ }^{22}$ while flying in visibilities as low as $300 \mathrm{RVR}$ as well as performance in response to off-nominal approach events (e.g., EFVS HUD failure) and departure events (e.g., RTO ${ }^{23}$ have been published elsewhere and are summarized below.

- Regardless of being hand-flown in visibilities as low as $300 \mathrm{RVR}$, each dual sensor EFVS concept tested resulted in excellent approach path tracking and touchdown performance without any penalty in crew workload. Comparable flight performance, touchdown performance and crew workload were observed between the baseline operational condition (Conventional HUD flown in 1800 RVR) and the EFVS concepts flown. Adding SV imagery to EFVS concepts provided situation awareness improvements but no discernible improvements in flight path maintenance.

- No go arounds were performed, except in response to failures, for any combination of EFVS concept (Blended, Slant Range), visibility level (300 ft, $700 \mathrm{ft}$ ), or airport lighting configuration (with or without TDZ/CL lights) tested. Based solely on the EV imagery, crews were able to identify the required visual landing references to continue the approach to landing.

- All landings, both nominal and those conducted during failure conditions, were within visual performance standards of the first third of the runway and within the lateral confines of the runway. Similarly, none of the RTO runs while using a dual sensor EFVS concept (with or without SV) on runways without CLL resulted in an excursion off the runway.

- Post-test, pilots commented that either method (Blended or Slant Range) of combining FLIR and MMWR imagery was acceptable for conducting approaches in low visibility conditions.

This paper details the departure performance and rollout to safe taxi speed performance while conducting nominal experiment runs.

Linear Mixed Models (LMMs) were applied in the analysis. The random factor was crew. By-subject variance due to individual differences was accounted for by using a Random Intercept Model in the LMM analyses. Unless otherwise specified, all LMMs: 1) employed the Identity (constant variance and independent residuals) covariance structure for the residuals; 2) were estimated with restricted maximum likelihood; and, 3) met the assumptions of normality and constant variance for the residuals and for the random effects.

The dependent variables assessed for departure performance were root-mean-square (RMS) centerline deviation during takeoff roll (measured in $\mathrm{ft}$ ), maximum lateral deviation from centerline during takeoff roll (measured in $\mathrm{ft}$ ), and RMS departure heading deviation during climbout (measured in degrees). Takeoff roll was measured from when groundspeed was greater than 40 knots (kts) until weight on wheels went to $0 \mathrm{lbs}$. 
The dependent variables evaluated for rollout to a safe taxi speed performance were 1) RMS centerline deviation (in feet) and maximum lateral deviation from centerline (in feet) during rollout (measured from touchdown to 60 kts groundspeed); 2) runway occupancy time (in seconds) as measured from threshold crossing until ownship tail crossed runway edge line; and 3) runway exit ground speed (in kts).

Two runways, $18 \mathrm{~L}$ and $18 \mathrm{C}$, were used to make approaches to runways with Category 1 lighting (MALSR and no TDZ/CLL). The conventional HUD in 1800 RVR (operational baseline), Blended EFVS (in 700 and 1000 RVR) and Slant Range EFVS (in 700 and $1000 \mathrm{RVR}$ ) approach runs were flown to $9000-\mathrm{ft}$ long runway 18L and the crews were instructed to exit at taxiway S2 (high-speed turnoff), if able. The Blended EFVS and Slant Range EFVS concepts (were flown in 300 RVR) and three CVS concepts (SVS/Blended, SVS/Timed Insert of Blended, and SVS/Slant Range) were flown in 300 and 700 RVR to 11120-ft long Runway 18C. Crews were instructed to exit Runway 18C at taxiway C1 (high-speed turnoff), if able.

Separate LMM analyses were conducted for Runway 18L and 18C for runway occupancy time and runway exit groundspeed (at S2 and C1, respectively).

Subjective measures included post-run workload using the Air Force Flight Test Center (AFFTC) ${ }^{24}$ rating and Likert-type questions of the utility of the display concepts for rollout, taxi, and departure.

\subsection{Departure performance - VS imagery and centerline lighting effects}

The effects of using dual sensor (FLIR and MMWR) EFVS imagery on a HUD while conducting standard instrument departure procedures on runways without centerline lighting in 300 RVR was assessed with comparison to the operational baseline - 300 RVR with a HUD and centerline lighting.

The fixed factor was HUD VS concept (Conventional, Blended, SVS/Blended, Slant Range, and SVS/Slant Range). The operational baseline for these comparisons was a conventional HUD (symbology only, no EV) departing on a runway with centerline lighting in 300 RVR which is the lowest visibility currently authorized for takeoffs.

Both the operational baseline and EFVS/CVS departure runs employed HIRL, serviceable RCLM, front course localizer guidance, and an approved HUD takeoff guidance system. The difference between the two was the absence/presence of FLIR/MMWR imagery and runway CLL.

60 HUD runs were analyzed.

Path Performance:

LMM analyses revealed no significant HUD VS concept differences for RMS centerline deviation during takeoff roll (overall mean $=3 \mathrm{ft}$ ), maximum lateral distance from centerline during takeoff roll (overall mean=6 ft), or RMS initial departure heading deviation during climbout (overall mean=2.2 degrees). Figure 9 shows boxplots of the RMS centerline deviation and maximum lateral distance from centerline during takeoff roll and Figure 10 shows the boxplot of RMS initial departure heading deviation during climbout. 

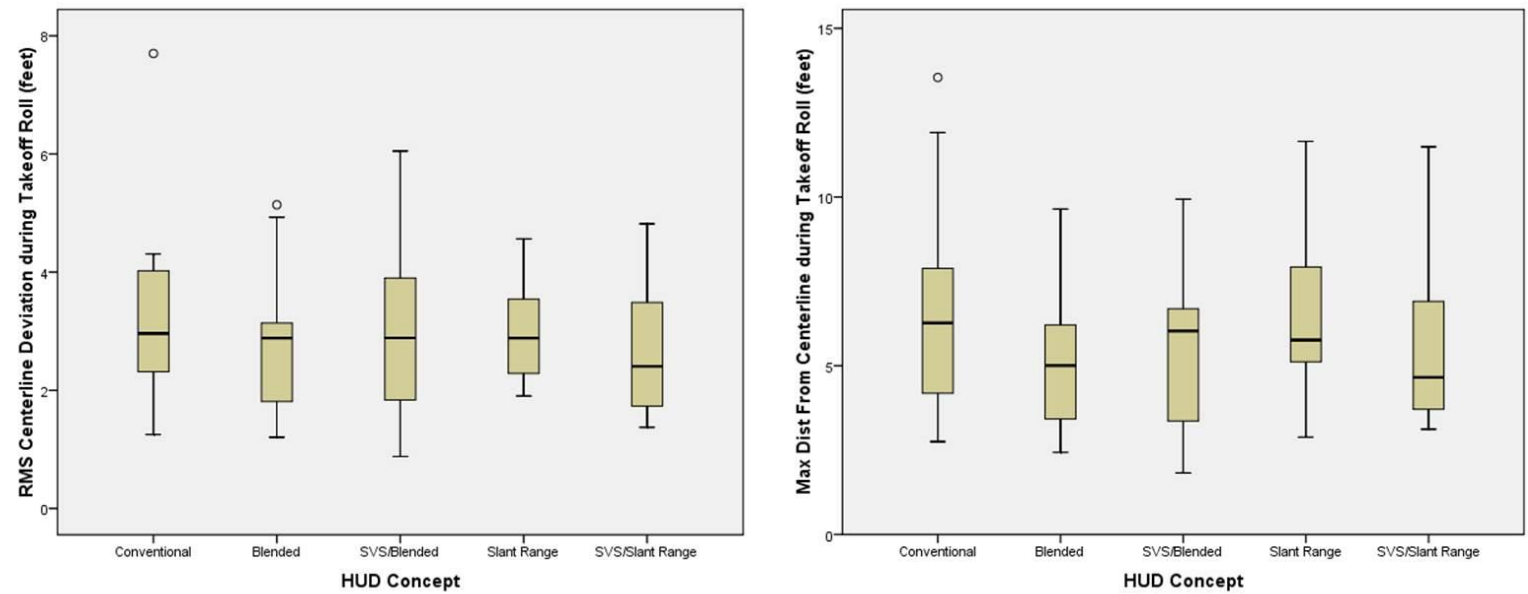

Figure 9. Boxplots of RMS centerline deviation during takeoff roll (left side) and maximum lateral distance from centerline during takeoff roll (right side).

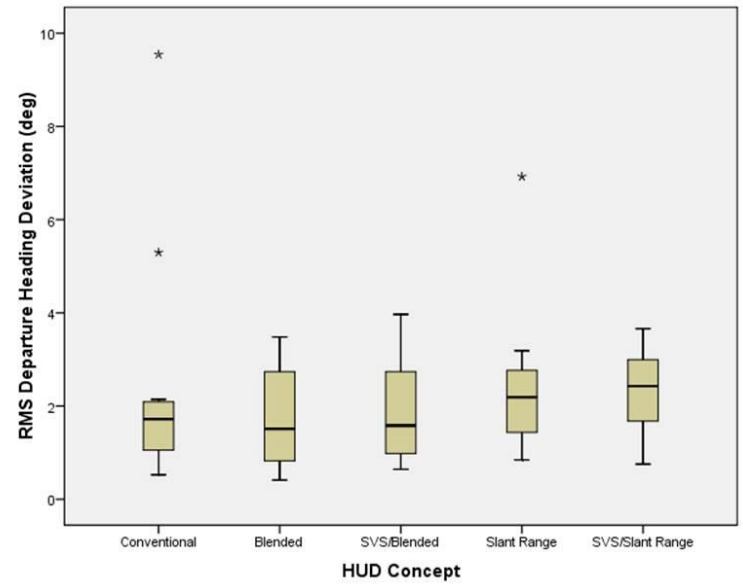

Figure 10. Boxplot of RMS initial departure heading deviation

\section{Crew Workload:}

Independent analyses revealed no significant PF or PM AFFTC workload rating differences for HUD VS concept ( $\mathrm{p}>0.05)$. The overall mean PF workload rating was 2.9 indicating workload was moderate and easily managed. The overall mean PM workload rating was 2.5 indicating workload was light to moderate with minimal demand.

\section{Post-run Ratings for Taxi and Departure Operations:}

Only post-run Taxi Question 3 ("I was able to safely taxi the aircraft") ratings were applicable for this analysis since it includes the Conventional HUD without imagery. Post-run Taxi Questions 1 and 2 refer to the EFVS concepts only.

LMM analyses revealed no significant PF or PM Taxi Question 3 rating differences for HUD VS concept ( $\mathrm{p}>0.05$ ). Both the PF (mean, $M=6.5)$ and PM (M=6.2) agreed that they were able to safely taxi the aircraft while using any of the EFVS concepts in 300 RVR to a runway without centerline lights.

Similarly, post-run Departure Questions 2-4 were included in this analyses, but Departure Question 1 was not as it applied to EFVS concepts only.

LMM analysis of PM Departure Question 2 ratings revealed that the Conventional HUD (M=6.0) was significantly different that the 4 EFVS concepts evaluated $(M=6.4)$. Operationally, however, these differences are inconsequential. There were no significant HUD VS concept differences for PF Departure Question 2 ratings ( $>0.05$, overall mean, 


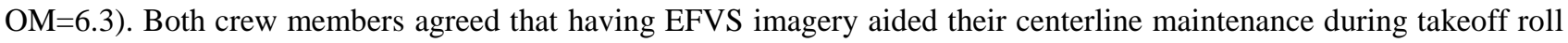
when taking off from a runway without CLL in 300 RVR conditions.

LMM analyses revealed no significant HUD VS concept differences ( $p>0.05$ ) for PF Departure Question 2 ratings $(\mathrm{OM}=6.3)$, Question 3 ratings $(\mathrm{OM}=6.3)$ and Question 4 ratings $(\mathrm{OM}=6.7)$ or PM Departure Question 3 ratings $(\mathrm{OM}=6.2)$ and Question 4 ratings $(\mathrm{OM}=6.5)$. Both crew members agreed that they were able to maintain runway heading during climbout (Question 3) and safely complete the departure (Question 4) while using an EFVS concept in 300 RVR conditions.

\section{Discussion:}

The path tracking, pilot workload, and subjective measures data all show that the tested EFVS concepts can provide equivalent levels of performance to the presence of runway CLL. EFVS imagery on the HUD allowed pilots to have excellent tracking of centerline during takeoff roll on a runway without centerline lighting in 300 RVR conditions. Furthermore, EFVS imagery did not interfere with their ability to safely complete an RTO as all were handled within the lateral confines of the runway for all conditions tested. ${ }^{23}$ None of the departures had excursions beyond operational significance and any lateral excursions during engine failures were quickly corrected to centerline. ${ }^{23}$ Crew workload was moderate in all conditions and easily managed while completing the departure. Additionally, having EFVS imagery did not interfere with their ability to maintain initial departure heading during climbout and it was reported that it helped them to safely complete the departure.

Adding SV imagery to EFVS concepts provided no discernible improvements in departure performance and incurred no workload penalties. However, pilots commented that having SVS during surface operations provided improvements in situation awareness (SA) as they could anticipate and visualize turns better with the larger FOV provided by the SVS imagery filling the HUD beyond the smaller EV imagery window inset. Both crew members agreed that EFVS imagery independent of SVS - enabled them to taxi safely and aided their ability to track the centerline.

\subsection{Rollout to safe taxi speed performance - EFVS imagery effects}

The effects of using dual sensor (FLIR and MMWR) EFVS imagery on a HUD during landing rollout to a safe taxi speed on runways with Category I lighting was assessed. The operational baseline for these comparisons was the conventional HUD (symbology only, no EV) flown in 1800 RVR which is the lowest visibility authorized to manually fly a HUD for Cat 1 approach with $200 \mathrm{ft} \mathrm{DH}$. For this baseline condition, below the DA/DH, the pilot's primary reference for maneuvering the aircraft was the OTW visual cues (i.e., natural vision). In the case of an EFVS, the pilot's primary reference for maneuvering the aircraft was the enhanced flight vision cues. For a HUD EFVS configuration to be considered for operational approval to use EFVS in lieu of natural vision to descend below the DA/DH and land and rollout, equivalent performance to an approach where natural vision is relied on below the DA/DH must be demonstrated.

60 HUD runs were considered in centerline tracking during rollout analyses and crew AFFTC workload ratings. The fixed factor was HUD operational concept (Conventional/1800 RVR, Blended in 300 or 700 RVR, Slant Range in 300 or 700 RVR).

\section{Rollout Performance:}

The Diagonal (unequal variance and independent residuals) covariance structure was employed for RMS lateral deviation from centerline LMM.

LMM analyses revealed HUD operational concept differences for RMS centerline deviation during rollout $(\mathrm{F}(4,55)=8.613$, $\mathrm{p}<0.001)$ and maximum lateral deviation from centerline during rollout $(\mathrm{F}(4,55)=8.018, \mathrm{p}<0.001)$. The Conventional HUD in 1800 RVR had significantly more RMS centerline deviation $(\mathrm{M}=7.8 \mathrm{ft}$ ) and maximum lateral deviation from centerline $(\mathrm{M}=15 \mathrm{ft})$ than the 4 EFVS operational concepts tested in extremely low visibilities (RMS centerline deviation, OM=4.6 $\mathrm{ft}$ and max lateral deviation. $\mathrm{OM}=9 \mathrm{ft}$ ). There were no significant operational differences between the 4 EFVS operational concepts for either of these lateral deviation from centerline during rollout measures.

Runway Occupancy Time and Exit Groundspeed:

72 Runway 18L approach runs were used in the runway occupancy time analysis; 71 were used in the runway exit ground speed analysis. For one run, the crew exited the runway beyond the S2 turnoff. The Conventional HUD in 1800 RVR (operational baseline), Blended EFVS (in 700 and 1000 RVR) and Slant Range EFVS (in 700 and 1000 RVR) approach runs were flown to Runway 18L. 
LMM analyses for 18L approach runs revealed no significant HUD operational concept differences ( $p>0.05)$ for runway occupancy time $(\mathrm{OM}=48 \mathrm{sec})$ or runway exit groundspeed $(\mathrm{OM}=30$ knots). The Slant Range and Blended EFVS concepts flown in 300 RVR had comparable runway occupancy time and runway exit groundspeeds as the Conventional HUD/1800 RVR operational baseline.

\section{Crew Workload:}

Independent analyses revealed no significant PF or PM AFFTC workload rating differences for HUD operational concept ( $\mathrm{p}>0.05)$. The overall mean PF workload rating was 3.2 indicating workload was moderate and easily managed. The overall mean PM workload rating was 2.7 indicating workload was light to moderate with minimal demand.

Discussion:

The centerline tracking and pilot workload for landing roll-out show that the tested EFVS concepts can provide equivalent levels of performance to the presence of runway CLL. Comparable centerline deviation during rollout performance and runway exit groundspeed performance were observed between the baseline operational condition (conventional HUD in 1800 RVR) and the EFVS operational concepts (Blended in 300 or 700 RVR, Slant Range in 300 or 700 RVR) as pilot flew approaches to runways without TDZ/CL lights. Based solely on the EV imagery, crews were able to achieve excellent centerline tracking during rollout and maintain VFR-like operational tempos for runway exit in visibilities as low as 300 RVR.

\subsection{Rollout performance to Safe Taxi Speed - Synthetic Vision effects}

The effects of adding SV to the EFVS imagery on a HUD during landing rollout on runways with Cat I lighting was assessed.

The fixed factors were HUD VS concept (Blended, SVS/Blended, SVS with Timed Insert Blended, Slant Range, and SVS/Slant Range) and visibility level (300, 700 RVR). 119 EFVS/CVS HUD approaches were considered in these analyses. One go-around was safely performed while flying the SVS/Blended CVS concept to a runway without TDZ/CL lights in the $300 \mathrm{ft}$ OTW visibility level. Review of run notes revealed that the PF said "something flickered and I did a go around. Then right after that I had everything I needed [to continue approach]." The video file was unavailable for review to see what may have "flickered" in the scene that triggered the PF to initiate a go-around.

Rollout Performance:

LMM analyses $(F(1,98)=39.356, \mathrm{p}<0.001)$ revealed that the $300 \mathrm{RVR}$ condition $(\mathrm{M}=3.9 \mathrm{ft})$ had significantly smaller RMS centerline deviation than the 700 RVR condition $(M=6.1 \mathrm{ft}$ ). There were no significant HUD VS concept differences ( $>0.05)$ or second order interaction for this measure.

Similarly, LMM analyses $(F(1,98)=40.449, \mathrm{p}<0.001)$ revealed that the $300 \mathrm{RVR}$ condition $(\mathrm{M}=8 \mathrm{ft})$ had significantly less maximum lateral distance from centerline than the $700 \mathrm{RVR}$ condition $(\mathrm{M}=12 \mathrm{ft})$. Operationally, these differences are inconsequential as there was excellent tracking of the centerline during rollout in both 300 and 700 RVR conditions. There were no significant $(\mathrm{p}>0.05)$ HUD VS concept differences or second order interaction for this measure.

Runway Occupancy Time and Exit Groundspeed:

96 Runway 18C approach runs were used in the runway occupancy time analyses; while 93 were used in the runway exit ground speed analyses. For three runs, the crew exited the runway beyond the Taxiway $\mathrm{C} 1$ turnoff. The Blended EFVS and Slant Range EFVS concepts (flown in 300 RVR) and three CVS concepts (SVS/Blended, SVS/Timed Insert Blended, and SVS/Slant Range) were flown in 300 and 700 RVR to Runway 18C.

LMM analyses for $18 \mathrm{C}$ approach runs revealed no significant ( $p>0.05$ ) operational concept differences for runway occupancy time $(\mathrm{OM}=76 \mathrm{sec})$ or runway exit groundspeed $(\mathrm{OM}=29$ knots). Adding SVS imagery to the EFVS concepts had no effect on runway occupancy time or runway exit ground speed in visibilities as low as 300 RVR.

Crew Workload:

The PF AFFTC workload ratings were significantly different for OTW visibility level. Pilots reported a lower workload when flying in 700 RVR condition (M=2.9) compared to when flying with 300 RVR condition $(M=3.3)$; however, these differences are operationally inconsequential. An AFFTC rating of 3 indicates the PF had moderate activity which was 
easily managed with considerable spare time available. There were no significant PF workload rating differences for VS concept or the second order interaction.

There were no significant PM AFFTC workload rating differences for the main factors $(p>0.05)$ or their interactions. The overall mean was reported to be 2.6 indicating PM workload was light to moderate and easily managed.

Discussion:

No workload, tracking of centerline during landing rollout, runway occupancy time or runway exit ground speed performance differences were observed with the addition of synthetic vision imagery to the dual sensor EFVS concepts. Crews were able to repeatedly achieve excellent tracking of the centerline while maintaining VFR-like operational tempos for runway exit with each of the HUD VS concepts hand-flown in extremely low visibility conditions to runways without TDZ/CL lighting. Even in these low visibility conditions to a runway with Cat I lighting, pilots reported that their workload was easily managed with spare time available to attend to other activities. Although no performance differences were observed in the data, pilot comments revealed that they preferred having SVS imagery with the EFVS concepts as it increased their HUD's FOV and provided improvements in situation awareness (SA).

\section{DISCUSSION}

The findings suggest conducting dual-sensor EFVS HUD approache ${ }^{22}$ and departures to runways with Category I lighting in extremely low visibility conditions appears feasible. No go-arounds were performed for the EFVS approaches, except due to induced failures. Regardless of OTW visibility level, all EFVS HUD approaches flown had comparable ILS tracking during the instrument segment, were within the lateral confines of the runway with acceptable sink rates during the visual segment of the approach, resulted in touchdowns within autoland tolerances, had excellent tracking of the centerline during rollout, and VFR-like tempos when exiting the runway. There were no flight performance improvements with the addition of synthetic imagery on the EFVS HUD but the pilots felt it provided situation awareness improvements during initial approach operations and taxi operations.

The experiment fundamentally addressed three main questions:

- Can a vision system in $300 \mathrm{ft} R V R$ conditions provide equivalent levels of safety and performance to current-day Category 1 operations? The data suggests that the performance of the EFVS concepts in visibilities as low as 300 $\mathrm{ft}$ RVR were no different than flying in $1800 \mathrm{ft}$ RVR with a HUD without EFVS. (This condition is the currentday lowest Category I visibility permissible.) These data suggest that the simulated EFVS operation from a flightdeck standpoint enables equivalent visual operations. For takeoff operations, the EFVS HUD provided equivalent levels of performance and safety as a HUD with low visibility takeoff guidance (which also requires a runway with centerline lights).

- Were there differences in the types of EFVS for $300 \mathrm{ft}$ RVR operations? The data suggests that there were no operationally significant differences in performance between the EFVS concepts. In particular, the minimal FOV concepts were acceptable. However, pilot comments indicate the addition of SVS (creating the CVS concepts) improved SA. During takeoff and surface operations, the improved SA from the addition of SVS primarily manifested itself in taxi operations for turns.

- Can a vision system remove the runway centerline lighting requirement for departures in 300 RVR conditions? This issue is important since under proposed rule-making an EFVS-equipped aircraft and qualified crew could dispatch and continue an approach to a landing, even when the destination airport is below authorized minimums, solely through the use of an electronic (sensor) image since natural vision is no longer required with EFVS. EFVS-equipped aircraft and qualified crew will be able to land but not depart in 300 RVR conditions unless runway centerline lighting is available. The data suggests that there were no operationally significant differences as the centerline lighting system varied. For the EFVS concepts tested, the absence of runway centerline lighting did not create any operationally significant differences in departure performance or crew workload. This result suggests that equivalent visual operations - i.e., operations as low as $300 \mathrm{ft}$ RVR enabled by the use of EFVS can be employed to all runways with a minimum of runway infrastructure.

A few caveats should be considered when interpreting these results. There was no intentional misalignment with the FLIR or MMWR sensors in this simulation. It was assumed that sensor misalignments could be resolved by onboard processing. Additionally, the sensors were modeled with the same update rate. There was also no navigation solution error in the 
simulation so the SVS imagery lined up well with the OTW scene. Lastly, this research has not addressed to date the implications of these technologies on the airport operation and air traffic control. Obviously, how air traffic control and the airport can provide effective oversight, management, and control during EVO-type operations is critical to safety and operation efficiency. This work is needed.

\section{CONCLUSIONS}

An experiment was conducted to investigate the use of vision system technologies, such as EFVS and SVS, as enabling technologies for future all-weather operations. The experimental objectives were to evaluate the operational feasibility, pilot workload and pilot acceptability of conducting instrument departures and instrument approaches to landing, touchdown, and rollout to a safe taxi speed in visibility as low as $300 \mathrm{ft}$ runway visual range by use of onboard vision system technologies on a HUD without need or reliance on natural vision. Crews evaluated two methods of combining dual sensor (millimeter wave radar and forward looking infrared) EFVS imagery on pilot-flying and pilot-monitoring HUDs as they made departures and approaches on runways with Category I lighting (MALSR ALS without touchdown zone and centerline lights). In addition, the impact of adding SV to the dual sensor EFVS imagery on crew flight performance and workload during extremely low visibility terminal operations was assessed. Results indicate that all EFVS concepts flown resulted in excellent approach path tracking, touchdown performance, runway centerline tracking during rollout and VFR-like speeds when exiting the runway without any workload penalty. Adding SV imagery to EFVS concepts provided situation awareness improvements but no discernible improvements in flight path maintenance.

Objective results indicate that making departures and approaches on runways with Category 1 lighting with a dual sensor EFVS HUD, with or without synthetic vision, in visibilities as low as 300 RVR appears feasible. Regardless of OTW visibility level tested, all EFVS HUD approaches flown had comparable ILS tracking during the instrument segment, were within the lateral confines of the runway with acceptable sink rates during the visual segment of the approach, were landed within the touchdown zone, and had comparable centerline tracking during rollout to a safe taxi speed. All twelve crews universally decided that the EFVS flown in 300 RVR conditions provided the necessary visual cues 1) to conduct a departure on a runway without centerline lights and 2) to acquire the required runway visual references at or before the decision height to continue a landing. Many crews had the required approach references as early as 500 feet. Most crews commented they wanted this system immediately and it was a significant improvement over current low visibility takeoff and landing systems.

No operationally relevant path maintenance differences were found due to the absence or presence of SV imagery on the EFVS HUDs. Pilots preferred having SV with the EFVS imagery on the HUD for low visibility terminal operations.

FLIR sensor technology used in conjunction with MMWR on the HUD enabled successful departures and approaches, without any workload penalty, in visibility as low as 300 RVR in this simulation experiment. Future research should include failure of sensor systems during departure, sensor characteristics such as latency, and study of EFVS during LVO/SMGCS operations.

\section{ACKNOWLEDGEMENTS}

The authors would like to thank Terry King, Chris Hope, Sean Flack and others associated with the FAA AFS-410 for reuse of OpSpec 078/079 table highlighting operational credit for lower than standard take-off minima.

Thanks also to NASA's Simulation Development and Analysis Branch (specifically Jerry Karwac, Jim Barnes, and Ben Lewis) for creating the simulation, display concepts, and conducting data collection for this experiment. A special thanks also to Regina Johns for arranging and assisting with subject scheduling and travel arrangements.

\section{REFERENCES}

[1] Joint Planning and Development Office, 2008, Next Generation Air Transportation System Integrated Plan: A Functional Outline, Washington, DC.

[2] Chin, D.K., Goldberg, J., and Tang, T., "Airport Surface Delays and Causes: A Preliminary Analysis." NASA/CR97-201721, 1997.

[3] Allan, S. S., Beesley, J. A., Evans, J. E., and Gaddy, S. G., “Analysis of delay causality at Newark International Airport.” In 4th USA/Europe Air Traffic Management R\&D Seminar. Dec 2001. 
[4] Dzikus, N., Wollenheit, R., Schaefer, M,. and Gollnick, V., "The Benefit of Innovative Taxi Concepts: The Impact of Airport Size, Fleet Mix and Traffic Growth," paper presented at the 2013 Aviation Technology, Integration, and Operations Conference, AIAA paper no. 2013-4212, 2013.

[5] Arthur, J. J., III, Prinzel, L. J., III, Kramer, L. J., Bailey, R. E., and Parrish, R. V. (2003). CFIT prevention using synthetic vision. Proceedings of SPIE, Enhanced and Synthetic Vision 2003, 5018, 146-157.

[6] Schiefele, J., Howland, D., Maris, J., Pschierer, C., Wipplinger, P., and Meuter, M. (2005) Human factors flight trial analysis for 3D SVS: Part II. Proceedings of SPIE, Enhanced and Synthetic Vision 2005, 5802, 195-206.

[7] Kramer, L. J., Prinzel, L. J., III, Bailey, R. E., and Arthur, J. J., III (2003). Synthetic vision enhances situation awareness and RNP capabilities for terrain-challenged approaches. Proceedings of the American Institute of Aeronautics and Astronautics Third Aviation Technology, Integration, and Operations Technical Forum, AIAA 20036814, 1-11.

[8] French, G. and Schnell, T. (2003). Terrain awareness \& pathway guidance for head-up displays (TAPGUIDE): a simulator study of pilot performance. Proceedings of 22nd IEEE/AIAA Digital Avionics Systems Conference, 2, pp. 9.C.4 - 9.1-7.

[9] Schnell, T., Keller, M., and Etherington, T. (2009). Trade-offs in synthetic vision systems display resolution, field of regard, terrain data density, texture, and shading during off path operations. The International Journal of Aviation Psychology, pp. 33-48.

[10] Lemos, K. and Schnell, T. (2003). Synthetic vision systems: human performance assessment of the influence of terrain density and texture. Proceedings of 22nd IEEE/AIAA Digital Avionics Systems Conference, 2, pp. 9.E.3 - 9110.

[11] Alexander, A. L., Wickens, C. D., and Hardy, T. J. (2005). Synthetic vision systems: the effects of guidance symbology,

[12] Kramer, L. J., Williams, S. P., and Bailey, R. E. (2008). Simulation evaluation of synthetic vision as an enabling technology for equivalent visual operations. Proceedings of SPIE, Enhanced and Synthetic Vision Conference 2008, 6957, 1-15.

[13] McKenna, Ed. "Synthetic Vision Systems.” Avionics Magazine, May 2012, pp. 20-23.

[14] Connor, Glenn. “On the Road to Zero-Zero.” Professional Pilot Magazine, April 2011.

[15] Minimum Aviation System Performance Standards (MASPS) for Enhanced Vision Systems, Synthetic Vision Systems, Combined Vision Systems and Enhanced Flight Vision Systems. RTCA/DO-315, RTCA Inc. Washington, DC. Dec 2008.

[16] Federal Aviation Administration, Revisions to Operational Requirements for the Use of Enhanced Flight Vision Systems (EFVS) and to Pilot Compartment View Requirements for Vision Systems, Retrieved April 27, 2015 from https://federalregister.gov/a/2013-13454.

[17] Glenn Connor. NASA studies advanced EFVS sensor models with dual HUD flightdeck for landing in $300 \mathrm{ft}$ RVR. Professional Pilot. October 2014, pp. 98-102.

[18] Bailey, R. E., Kramer, L. J., and Williams, S. P. (2010). Enhanced vision for all-weather operations under NextGen. Proceedings of SPIE Enhanced and Synthetic Vision Conference 2010, 7689, pp. 768903-1-768903-18.

[19] Kramer, L. J., Harrison, S. J., Bailey, R. E., Shelton, K. J., and Ellis, K. K. (2014). Visual advantage of enhanced flight vision system during NextGen flight test evaluation. Proceedings of SPIE Degraded Visual Environments: Enhanced, Synthetic, and External Vision Solutions 2014, 9087, pp. 90870G-90870G-18.

[20] Minimum Aviation System Performance Standards (MASPS) for an Enhanced Flight Vision System to Enable AllWeather Approach, Landing and Roll-Out to a Safe Taxi Speed. RTCA/DO-341, RTCA Inc. Washington, DC. Sept 2012.

[21] Kramer, L. J., Bailey, R. E., Ellis, K. K., Williams, S. P., Arthur, J. J., III, Prinzel, L. J., III, \& Shelton, K. J. (2013). Enhanced flight vision systems and synthetic vision systems for NextGen approach and landing operations (NASA Technical Publication 218054). Washington, DC: NASA

[22] Kramer, L. J., Etherington, T. J., Severance, K., Bailey, R. E., Williams, S. P., and Harrison, S. J. (2015). Assessing Dual Sensor Enhanced Flight Vision Systems to Enable Equivalent Visual Operations, AIAA Infotech @ Aerospace, AIAA SciTech, (AIAA 2016-2044).

[23] Etherington, T. J., Kramer, L. J., Severance, K., Bailey, R. E., Williams, S. P., and Harrison, S. J. (2015). Enhanced flight vision systems operational feasibility study using radar and infrared sensors. Proceedings of the 34th Digital Avionics Systems Conference.

[24] Ames, Lawrence L. \& George, Edward J. (1993). Revision and verification of a seven-point workload estimation scale. Air Force Flight Test Center: AFFTC-TIM-93-01. 
[25] Vidulich, M. A. and Hughes, E. R. (1991). Testing a subjective metric of situation awareness. Proceedings of the Human Factors \& Ergonomics Society, 35th Annual Meeting, 1307-1311. 